Indonesian Journal of Physics

Vol 20 No. 2, April 2009

\title{
A Comparison of Zinc and Carbon Doped on the Atomic Interdiffusion of InGaAs/AlGaAs Quantum Wells Laser Structures After Annealing
}

\author{
Paulus L. Gareso \\ Departement of Physics, \\ Faculty of Mathematics and Natural Sciences, \\ Hasanuddin University, \\ Jl. Perintis Kemerdekaan Km 10 Tamalanrea 90245, Makassar \\ e-mail:pgareso@fmipa.unhas.ac.id
}

\begin{abstract}
We have compared a zinc and a carbon doped on the atomic interdiffusion of InGaAs/AlGaAs after annealing using Electrochemical capacitance voltage (EC-V), X-ray diffraction and photoluminescence (PL) measurements. Electrochemical capacitance voltage measurements revealed that the carrier concentration in the $\mathrm{Zn}$-doped $p^{++}$GaAs contact layers decreased after annealing at $900^{\circ} \mathrm{C}$ for $60 \mathrm{sec}$, indicating that some of the Zn acceptors were passivated or outdiffused from the surface. In contrast to the C-doped samples, an increase of carrier concentration was observed after annealing. X-ray rocking curve confirmed this result where the amount of lattice contraction increase after annealing which is attributed to the presence of the substitutional carbon $C_{A s}$. Photoluminescence results showed that a large energy shift was observed in the Zn-doped samples compare with Cdoped samples. Photoluminescence measurements after etching to various depth showed similar luminescence defects in both $\mathrm{Zn}$ - and $\mathrm{C}$-doped samples. Photocurrent measurements showed the quality of quantum well was improve after annealing in $C$-doped samples due to activation of carbon doped.
\end{abstract}

Keywords: Atomic intermixing, Carbon doped, InGaAs/AlGaAs QWs

\section{Introduction}

Thermal annealing is an essential in semiconductor device processing technique and is particularly useful for intermixing where high temperature annealing is required to initiate the intermixing between the barrier and quantum well regions. On the other hand, the high temperature annealing required for intermixing could adversely affect the quality of quantum wells and thus the device performance. Despite of this disadvantage, quantum well intermixing (QWI) has been widely used to modify the bandgap energy through the intermixing of constituent atoms between the barrier and quantum well regions. In addition to this, QWI can be used to tailor the new devices and has found applications in semiconductor lasers, waveguides, and optoelectronic integrated circuits ${ }^{1)}$. There are several methods commonly used to initiate the well-barrier intermixing such as impurity induced disordering ${ }^{2}$, impurity-free vacancy disordering ${ }^{3)}$, and ion implantation induced disordering ${ }^{4)}$. All these methods rely on the diffusion of defects across the heterointerfaces to initiate the interdiffusion process. Many studies have reported the effect of dopants on the intermixing process ${ }^{2,5,6)}$, but the effect of dopant diffusion in actual optoelectronic devices has not received much attention.

In this report, we compare the atomic interdiffusion of InGaAs/AlGaAs/GaAs laser structures doped with zinc and carbon atoms after annealing. Thin $p$-clad InGaAs/AlGaAs QW laser structures were used for interdiffusion study. This particular structure uses an asymmetric design such that most of the optical field distribution lies in n-type layers, near the substrate and only small part of the distribution is found near the top surface. The lasing parameters of this type of structure are comparable with those of standard well-behaved symmetric structures. In addition, this structure is well suited for intermixing in GaAs based system, where the diffusion length of $\mathrm{Ga}$ vacancies is of the order of 0.1 $\mu \mathrm{m}$. For interdiffusion study, the InGaAs/AlGaAs laser structures were annealed at various temperatures in the range of $875-925^{\circ} \mathrm{C}$ to initiate the interdiffusion between the quantum well and barrier region as well as to measure the ability of the samples to retain their physical properties after thermal processing. Generally, photoluminescence measurements such as the PL intensity and PL line width were used to observe the change of samples properties after interdiffusion. The laser structures used in this study were doped with zinc and carbon atoms. Carbon is known to have less diffusity in GaAs-based materials in comparison to the zinc $^{7-9)}$. The degree of interdiffusion in both samples was also investigated.

\section{Experiment}

The laser structures used in this work were grown on $n^{+} \mathrm{GaAs}$ substrates using low pressure metalorganic chemical vapor deposition (LP-MOCVD). The details of these asymmetric InGaAs/AlGaAs laser structures have previously been reported ${ }^{10)}$. Two different structures were grown that differed only by the type of dopant used for p-type contact and cladding layers, in one case they were doped with $\mathrm{Zn}$ and in other C. Details of the structures are summarized in Table 1. After growth, the two samples were annealed under Ar flow in a rapid thermal 
annealer at temperatures in the range of $875-925^{\circ} \mathrm{C}$ for $60 \mathrm{sec}$. During annealing the sample surfaces were protected using the GaAs proximity capping method to minimize arsenic loss. Photoluminescence (PL) measurements were performed at $77 \mathrm{~K}$ to monitor the extent of quantum well intermixing. The PL set-up consisted of a frequency-doubled diode-pumped solidstate laser (at $532 \mathrm{~nm}$ ) for excitation and an InGaAs photodetector at the output slit of a $0.5 \mathrm{~m}$ monochromator. Doping profiles were measured using a Bio-Rad electrochemical voltage (EC-V) profiler model PN-4300PC. Finally, the sample strain was measured by Double-crystal X-ray diffraction (DCXRD) using a Bede QC2a system.

Table 1. Details of the layers of the asymmetric InGaAs/AlGaAs laser structures used in this work

\begin{tabular}{|c|c|c|c|}
\hline Layer Type & $\begin{array}{c}\text { Al composition } \\
\text { index }\end{array}$ & Thickness & Doping \\
\hline$p^{++} \mathrm{GaAs}$ & 0.00 & $0.10 \mu \mathrm{m}$ & $\mathrm{C}>1 \times 10^{19} \mathrm{~cm}^{-3}$ \\
\hline$p \mathrm{Al}_{\mathrm{x}} \mathrm{Ga}_{1-\mathrm{x}} \mathrm{As}$ & 0.60 & $0.30 \mu \mathrm{m}$ & $\mathrm{C} \sim 1 \times 10^{18} \mathrm{~cm}^{-3}$ \\
\hline Grading $\mathrm{Al}_{\mathrm{x}} \mathrm{Ga}_{1-\mathrm{x}} \mathrm{As}$ & $0.60 \rightarrow 0.20$ & $0.16 \mu \mathrm{m}$ & undoped \\
\hline GaAs & 0.00 & $1.8 \mathrm{~nm}$ & undoped \\
\hline $\mathrm{In}_{0.20} \mathrm{Ga}_{0.80} \mathrm{As}$ & & $6 \mathrm{~nm}$ & undoped \\
\hline GaAs & 0.00 & $1.8 \mathrm{~nm}$ & undoped \\
\hline $\mathrm{Al}_{\mathrm{x}} \mathrm{Ga}_{1-\mathrm{x}} \mathrm{As}$ & 0.20 & $6 \mathrm{~nm}$ & undoped \\
\hline GaAs & 0.00 & $1.8 \mathrm{~nm}$ & undoped \\
\hline $\mathrm{In}_{0.20} \mathrm{Ga}_{0.80} \mathrm{As}$ & & $6 \mathrm{~nm}$ & undoped \\
\hline GaAs & 0.00 & $1.8 \mathrm{~nm}$ & undoped \\
\hline Grading $\mathrm{Al}_{\mathrm{x}} \mathrm{Ga}_{1-\mathrm{x}} \mathrm{As}$ & $0.20 \rightarrow 0.60$ & $0.16 \mu \mathrm{m}$ & undoped \\
\hline $\mathrm{Al}_{\mathrm{x}} \mathrm{Ga}_{1-\mathrm{x}} \mathrm{As}$ & 0.60 & $0.10 \mu \mathrm{m}$ & Si: $10^{17} \mathrm{~cm}^{-3}$ \\
\hline Grading $\mathrm{Al}_{\mathrm{x}} \mathrm{Ga}_{1-\mathrm{x}} \mathrm{As}$ & $0.60 \rightarrow 0.30$ & $0.02 \mu \mathrm{m}$ & Si: $10^{17} \mathrm{~cm}^{-3}$ \\
\hline $\mathrm{Al}_{\mathrm{x}} \mathrm{Ga}_{1-\mathrm{x}} \mathrm{As}$ & 0.30 & $0.22 \mu \mathrm{m}$ & Si: $10^{17} \mathrm{~cm}^{-3}$ \\
\hline Grading $\mathrm{Al}_{\mathrm{x}} \mathrm{Ga}_{1-\mathrm{x}} \mathrm{As}$ & $0.30 \rightarrow 0.45$ & $0.01 \mu \mathrm{m}$ & Si: $10^{17} \mathrm{~cm}^{-3}$ \\
\hline $\mathrm{Al}_{\mathrm{x}} \mathrm{Ga}_{1-\mathrm{x}} \mathrm{As}$ & 0.45 & $0.07 \mu \mathrm{m}$ & Si: $5 \times 10^{17} \mathrm{~cm}^{-3}$ \\
\hline $\begin{array}{l}\mathrm{Al}_{\mathrm{x}} \mathrm{Ga}_{1-\mathrm{x}} \mathrm{As} \\
n^{+} \text {substrate }\end{array}$ & 0.45 & $2.00 \mu \mathrm{m}$ & Si: $10^{18} \mathrm{~cm}^{-3}$ \\
\hline
\end{tabular}

\section{Results and Discussion}

\subsection{Electrochemical profilling}

Figure 1(a) and (b) show the carrier concentration as a function of depth for zinc and carbon doped samples, before and after annealing at $900^{\circ} \mathrm{C}$ for $60 \mathrm{sec}$. The first $0.1 \mu \mathrm{m}$ corresponds to the highly doped $p^{++} \mathrm{GaAs}$ contact layer, and the next 0.45 $\mu \mathrm{m}$ to the $\mathrm{p}$ AlGaAs cladding layer. Annealing significantly reduced the carrier concentration of the Zn-doped $\mathrm{p}++\mathrm{GaAs}$ layers. There was also a relatively small reduction in $\mathrm{Zn}$ concentration of the AlGaAs cladding layers after annealing. This reduction could be due to $\mathrm{Zn}$ acceptor compensation or through the loss of $\mathrm{Zn}$ from the surface ${ }^{11)}$. Very different results were observed for the samples doped with carbon. Annealing at $900^{\circ} \mathrm{C}$ increased the electrically active carrier concentration in the top $\mathrm{p}^{++} \mathrm{GaAs}$ layers and the AlGaAs cladding layers by about $29 \%$ and by $58 \%$, respectively. The increase of carrier concentration in the carbon doped sample is due to the removal of the $\mathrm{C}-\mathrm{C}$ interstitial pairs that have been reported previously ${ }^{12}$.

It is clearly seen from the EC-V results that very different behavior for zinc and carbon doped after annealing, suggesting that the diffusion mechanism involving is different. In the case of $\mathrm{Zn}$ doped samples, most studies of $\mathrm{Zn}$ diffusion in $\mathrm{Zn}$ doped III-V quantum well structures reported that $\mathrm{Zn}$ diffusion operates via the interstitial-substitutional mechanism. $\mathrm{Zn}$ atoms diffuse into the quantum well region as charge interstitial $\mathrm{Zn}_{\mathrm{i}}^{+}$and then move onto the group III atom sublattice to form immobile substitutional acceptor ${ }^{13)}$. There are two model that have been suggested for this. In the first model, the interstitial combines with a gallium vacancy to form the substitutional acceptor ${ }^{14)}$. According this model, 
the $\mathrm{Ga}$ concentration will reduce since $\mathrm{Zn}$ interdiffusion take up vacant $\mathrm{Ga}$ sites. The second model is the "Kick-Out"model. In this model, $\mathrm{Zn}$ interstitial become substitutional acceptors by making the $\mathrm{Ga}$ atoms interstitial ${ }^{15)}$. In our results, mostlikely that annealing the samples without an overpressure of $\mathrm{Zn}$ and As might cause $\mathrm{Zn}$ and As atoms outdiffusion from the sample surface. The outdiffusion of zinc and arsenic lead to in a reduction of zinc concentration in $p^{++}$contact layers. In the case of the C-doped samples, it is well known that carbon incorporates primarily as a substutitional acceptor on the As sublattice ${ }^{16-18)}$. Annealing the samples with proximity capping leads to outdiffusion of As ions. As a result, additional arsenic vacancies are created which is allowing an increase incorporation of carbon to the arsenic, and this explain the increased of carrier concentration in C-doped samples.
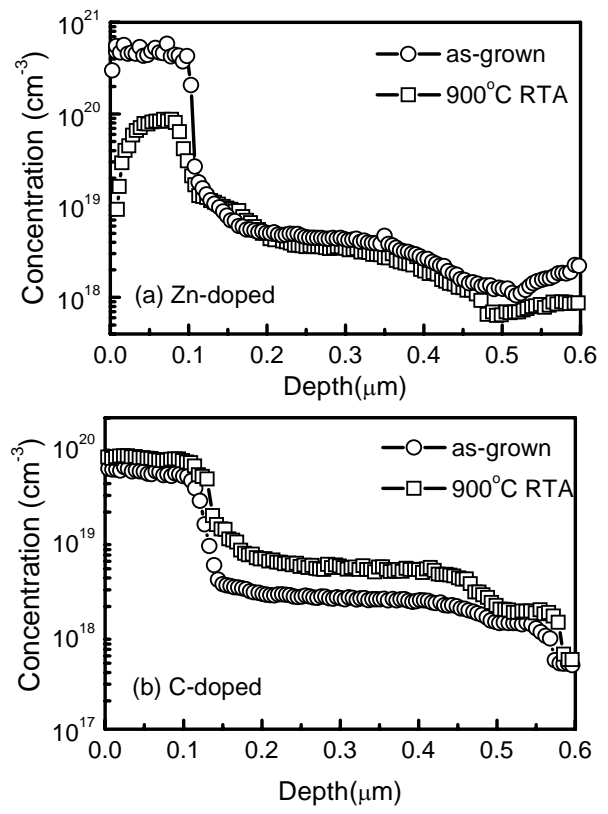

Figure 1. EC-V profile of carrier concentration of Znand $\mathrm{C}$-doped $\mathrm{InGaAs} / \mathrm{AlGaAs}$ laser structures before and after annealing at $900^{\circ} \mathrm{C}$ for $60 \mathrm{sec}$.

\subsection{X-ray diffraction}

The DCXRD rocking curves for $\mathrm{Zn}$ - and $\mathrm{C}$ doped samples before and after annealing at $900^{\circ} \mathrm{C}$ for $60 \mathrm{sec}$ are shown in Figure 2. The features appearing on the left hand side of the main (GaAs) peak are related to the AlGaAs layers. The curves for both asgrown samples look similar except for an additional small peak to the right of the main peak in the Cdoped sample. This peak is related to the slight tensile strain caused by the incorporation of the smaller $\mathrm{C}$ atoms in the highly doped $p^{++} \mathrm{GaAs}$ contact layer. It has been shown that if the carbon concentration is higher than about $10^{19} \mathrm{~cm}^{-3}$, it causes lattice contraction since carbon has a smaller covalent radius
$(0.77 \AA)$ compared to As $(1.20 \AA)$ or Ga $(1.26 \AA)^{19)}$. After annealing this peak becomes more pronounced (C-doped sample). This increase of lattice contraction by about $26 \%$ compared to the as-grown wafer is comparable to $29 \%$ electrical activation obtained from the EC-V measurement. In the case of $\mathrm{Zn}$-doped samples, annealing at $900^{\circ} \mathrm{C}$ for $60 \mathrm{sec}$ resulted in the smearing of the AlGaAs-related peaks. As shown in the next section, this is consistent with more pronounced intermixing caused by the interdiffusion of $\mathrm{Zn}$ across the $\mathrm{QW} /$ active region.

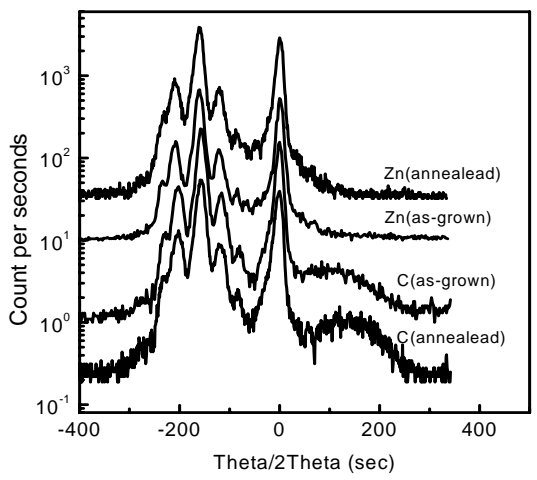

Figure 2. DCXRD spectra of $\mathrm{Zn}$ - and C-doped samples InGaAs/AlGaAs laser structures for as-grown and annealed samples.

\subsection{Photoluminescence}

Figure 3 shows the PL spectra of the $\mathrm{Zn}$ - and C-doped samples before and after annealing for $60 \mathrm{sec}$ at various temperature ranging from $875^{\circ} \mathrm{C}$ to $925^{\circ} \mathrm{C}$. The emission peak at $903 \mathrm{~nm}$ originates from the quantum well region. For the $\mathrm{Zn}$-doped sample (Figure 3a), the peak from the quantum well consistently shifted to shorter wavelength with increasing annealing temperature. Larger wavelength shift was observed after annealing at $925^{\circ} \mathrm{C}$ and was followed by a significant reduction in the PL intensity. In addition to this the PL linewidths progressively broadened with annealing temperature. The larger wavelength shift for the $\mathrm{Zn}$-doped samples is consistent with the higher $\mathrm{Zn}$ diffusivity in GaAs/AlGaAs. A smaller shoulder at $896 \mathrm{~nm}$ and a relatively broad peak at $942 \mathrm{~nm}$ were also observed after annealing at $925^{\circ} \mathrm{C}$. These peaks are attributed to radiative transitions from point defects which were thermally generated during annealing as discussed later.

In the case of C-doped samples (see Figure 3b), only a slight blueshift was observed after annealing at $875^{\circ} \mathrm{C}$ and $900^{\circ} \mathrm{C}$, while the PL intensities and PL linewidths are comparable to the as-grown samples. This indicates that only very little interdiffusion had occurred at these temperatures and the quality of the structures was preserved. At $925^{\circ} \mathrm{C}$, the PL intensity decreased and was accompanied by a relatively large wavelength shift and slight broadening of the 
linewidth. In comparison to the Zn-doped samples, we observed a much smaller atomic interdiffusion in the C-doped samples. This is due to group-III sublattice $(\mathrm{Al}, \mathrm{Ga})$ is the dominant mechanism involved, and the substitutional carbon on group-V sublattice may have little influence on the intermixing mechanism during annealing. In addition to this the substitutional $\mathrm{C}^{-}{ }_{\mathrm{As}}$ concentration in the $\mathrm{C}$-doped samples is much lower than zinc interstitial $\left(\mathrm{Zn}^{+}\right.$in the $\mathrm{Zn}$-doped samples). Similar to the Zn-doped samples, two smaller peaks at 896 and $942 \mathrm{~nm}$ were also observed in the C-doped samples annealed at $925^{\circ} \mathrm{C}$. In both the $\mathrm{Zn}$ - and Cdoped samples the broad peak at $896 \mathrm{~nm}(1.384 \mathrm{eV})$ disappears after removal of the top $p^{++} \mathrm{GaAs}$ contact layer. This peak may be related to a $\mathrm{Zn}_{\mathrm{Ga}}-\mathrm{V}_{\mathrm{As}}$ transition $(1.37 \mathrm{eV})^{20)}$ or to a $\mathrm{V}_{\mathrm{As}}-\mathrm{C}_{\mathrm{As}}$ transition $(1.41$ $\mathrm{eV})^{21)}$ in the top $\mathrm{p}^{++} \mathrm{GaAs}$ layer.
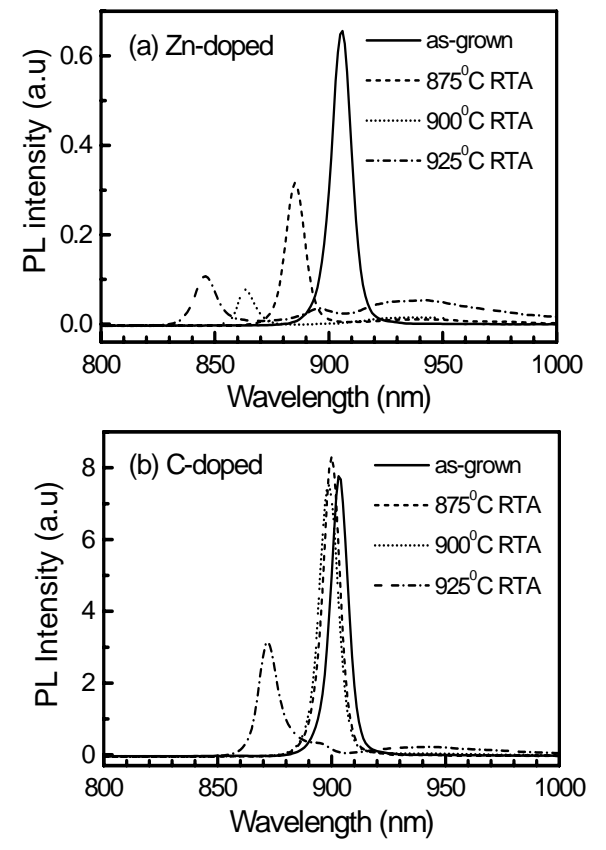

Figure 3. Low temperature photoluminescence spectra of $\mathrm{Zn}$ - and C-doped InGaAs/AlGaAs laser structures before and after annealing varying the temperature from $875^{\circ} \mathrm{C}$ to $925^{\circ} \mathrm{C}$.

In order to investigate the additional peaks that appear in the PL spectra, the samples were etched to either a depth of $0.2 \mu \mathrm{m}$ or $0.70 \mu \mathrm{m}$, corresponding to the removal of the top $\mathrm{p}^{++}$GaAs layer and the QWs, respectively and then annealed. Figure 4 shows the $77 \mathrm{~K}$ PL spectra of the etched samples taken before and after annealing at $925^{\circ} \mathrm{C}$. Only the QW peak at $906 \mathrm{~nm}$ was observed in both the as-grown $\mathrm{Zn}$ and Cdoped etched to a depth of $0.2 \mu \mathrm{m}$. In the as grown $\mathrm{Zn}$ - and C-doped samples etched to $0.7 \mu \mathrm{m}$ depth, two peaks at $943 \mathrm{~nm}(1.315 \mathrm{eV})$ and $1060 \mathrm{~nm}(1.170 \mathrm{eV})$ were observed. It should be noted at this depth, we were probing the n-AlGaAs layers. Clearly these two peaks were already present in the as-grown n-AlGaAs but were masked by the QW luminescence.

After annealing, the samples etched to a depth of $0.2 \mu \mathrm{m}$ annealed showed a blue shift of the QW emission and two additional peaks at $943 \mathrm{~nm}$ and $1254 \mathrm{~nm}$ were observed. However, in the $\mathrm{Zn}$-doped sample, the $943 \mathrm{~nm}$ peak was much stronger than that in the C-doped samples. Also after etching to depth of $0.7 \mu \mathrm{m}$ and annealing the intensity of the $943 \mathrm{~nm}$ peak is diminished. This suggests that it was related to a defect peak that was enhanced during the annealing step and its concentration was influenced by the type of dopant present in the sample. Furthermore, it was also observed in the n-AlGaAs layers (samples etched to $0.7 \mu \mathrm{m}$ ) before and after annealing. Hence, we attribute this peak to a point defect complex related to the group-III species. In GaAs, two emission are reported at $77 \mathrm{~K}, 1.32 \mathrm{eV}$ related to $\mathrm{Ga}^{2-}$ As and at 1.284 $\mathrm{eV}$ related to $\mathrm{Ga}_{\mathrm{As}}{ }^{22}$ ). Therefore it is possible that the peak observed at $943 \mathrm{~nm}$ is related to these antisites. However, there are few studies related to defect complexes in the case of moderate to high Al content AlGaAs.
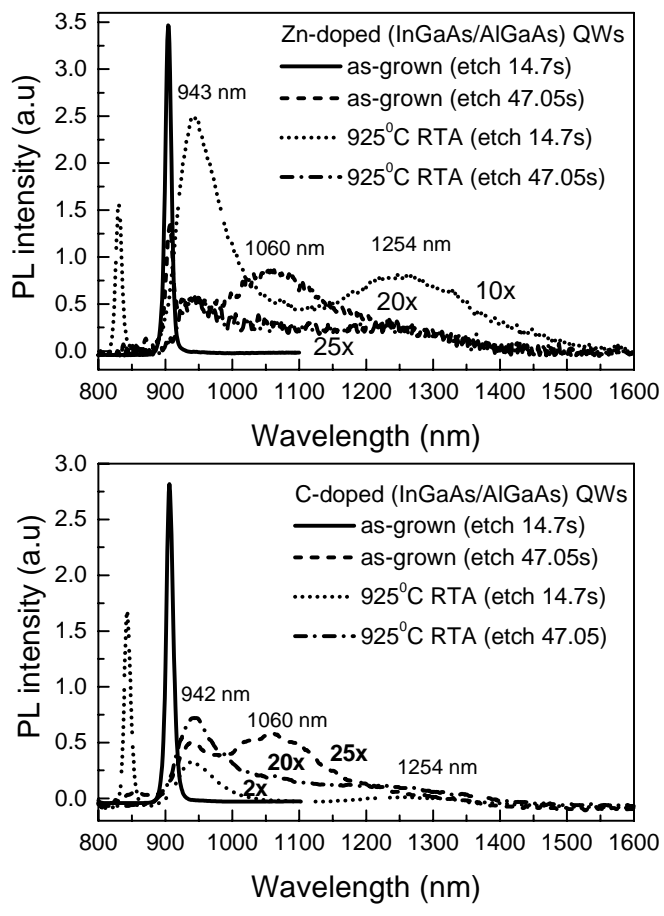

Figure 4. Low temperature photoluminescence spectra of $\mathrm{Zn}$ - and C-doped InGaAs/AlGaAs laser structures after etching surface of the samples to different depths

The peak at $1254 \mathrm{~nm}$ was also observed in moderately Si-doped GaAs samples $\left(5 \times 10^{16} \mathrm{~cm}^{-3}\right)^{23)}$. Several other studies have reported the presence of this peak at $77 \mathrm{~K}$ in $\mathrm{Si}$-doped GaAs and correlated it with $\mathrm{Si}_{\mathrm{Ga}-\mathrm{Si}_{\mathrm{As}}}$ complex ${ }^{24,25)}$. On the other hand, Liang et al., ${ }^{26)}$ interpreted this as the recombination luminescence of the donor-acceptor pairs $\mathrm{V}_{\mathrm{As}}-\mathrm{V}_{\mathrm{Ga}}$. In 
our case, this peak becomes only prominent after annealing. Furthermore, its intensity was stronger in the $\mathrm{Zn}$-doped compared to the C-doped sample. Although a lower intensity was observed in the samples etched to $0.7 \mu \mathrm{m}$ depth (i.e in the $n$-AlGaAs layers), it is unlikely that this peak is related to the $\mathrm{Si}_{\mathrm{Ga}}-\mathrm{Si}_{\mathrm{As}}$ complex in our case since it's intensity was stronger when the top p-AlGaAs layers were present.

For both $\mathrm{Zn}$ - and C-doped samples etched to $0.7 \mu \mathrm{m}$ after annealing, the $1060 \mathrm{~nm}$ peak diminishes in intensity and was accompanied by the appearance of the $1254 \mathrm{~nm}$ peak. This may be due to Si-related defect in $n$-AlGaAs since it was not observed in the $0.2 \mu \mathrm{m}$ etched samples. The intensity of the $943 \mathrm{~nm}$ peak remains essentially the same before and after annealing. The relatively stronger stability of this peak suggests that it might be due to more thermally stable defect, such as an antisite $\left(\mathrm{Ga}_{\mathrm{As}}\right)$ as discussed earlier. In the case of $\mathrm{Zn}$-doped samples, the defect/impurity related peaks are more prominent after annealing. Subsequently the quality of the QW luminescence is much inferior to that of the C-doped sample after intermixing. A summary of the observed defects peak for as-grown and annealed samples in both $\mathrm{Zn}$ - and Cdoped etched samples as shown in Table 2.

Table 2. The observed defects peak for as-grown and annealed samples in both $\mathrm{Zn}$ - and C-doped InGaAs/AlGaAs etched samples.

\begin{tabular}{ccc}
\hline \hline Etched depth & As-grown & Annealed \\
\hline $0.2 \mu \mathrm{m}(\mathrm{Zn})$ & No peaks & $943 \mathrm{~nm}$ and $1254 \mathrm{~nm}$ \\
$0.7 \mu \mathrm{m}(\mathrm{Zn})$ & $943 \mathrm{~nm}$ and & $943 \mathrm{~nm}$ and $1254 \mathrm{~nm}$ \\
& $1060 \mathrm{~nm}$ & \\
$0.2 \mu \mathrm{m}(\mathrm{C})$ & No peaks & $943 \mathrm{~nm}$ and $1254 \mathrm{~nm}$ \\
$0.7 \mu \mathrm{m}(\mathrm{C})$ & $943 \mathrm{~nm}$ and & $943 \mathrm{~nm}$ and $1254 \mathrm{~nm}$ \\
& $1060 \mathrm{~nm}$ \\
\hline \hline
\end{tabular}

\section{Conclusion}

A comparison of zinc and carbon doped on the atomic interdiffusion of $\mathrm{InGaAs} / \mathrm{AlGaAs} / \mathrm{GaAs}$ laser structures has been studied. The EC-V measurements show that some of the zinc acceptors are passivated or out-diffused from the surface after annealing while in contrast, part of the carbon dopant is activated. PL results from etched samples suggest the presence of higher concentration of point defects after annealing in the zinc doped sample than in the carbon doped samples. These point defects are responsible for degradation and larger blueshift of the QW emission in zinc doped sample in comparison to the carbon doped structures.

\section{Acknowledgements}

The authors would like to thank G. Joley and K. Sears for useful discussion. P.L.G acknowledges the scholarship funded by the Australian Agency for International Development (AusAID). Australian Research Council is gratefully acknowledged for the financial support.

\section{References}

1. E. H. Li, Quantum Well Intermixing for Photonic, SPIE Milestone Series, Bellingham, 1997. See also Semiconductor Quantum Wells Intermixing (Amsterdam: Gordon and Breach 2000).

2. D. G. Deppe and N. Holonyak, Jr., Atom Diffusion and Impurity-induced Layer Disordering in Quantum Well III-V Semiconductor Heterostructures, J. Appl. Phys. 64, R93, 1988.

3. J. H. Marsh, Quantum Well Intermixing, Semicond. Sci. Technol, 54, 1136, 1993.

4. H. H. Tan and C. Jagadish, Wavelength Shifting in GaAs Quantum Well Lasers by Proton Irradiation, Appl. Phys. Lett. 71, 2680, 1997.

5. L. J. Guido et al., Al-Ga Interdiffusion in Heavily Carbon-doped $\mathrm{Al}_{x} \mathrm{Ga}_{1-x} \mathrm{As}-\mathrm{GaAs}$ Quantum Well Heterostructures, J. Appl. Phys. 67, 2179, 1990.

6. I. Szafranek et al., Layer Intermixing in Heavily Carbon-doped AlGaAs/GaAs Superlattices, J. Appl. Phys. 68, 5615, 1990.

7. T. F. Kuech et al., Controlled Carbon Doping of GaAs by Metalorganic Vapor Phase Epitaxy, Appl. Phys. Lett. 53, 13171988.

8. C. R. Abernathy et al., Ultrahigh Doping of GaAs by Carbon During Metalorganic Molecular beam Epitaxy, J. Appl. Phys. Lett. 55, 1750, 1989.

9. K. Saito et al., Characterization of $p$-type GaAs Heavily Doped with Carbon Grown by Metalorganic Molecular-beam Epitaxy, J. Appl. Phys. 64, 3975, 1988.

10. M. Bud et al., Low loss, Thin p-clad 980-nm InGaAs Semiconductor Laser Diodes with an Asymmetric Structure Design, IEEE J. Quantum Electron. 39, 625, 2003.

11. N. H. Ky et al., Effects of Post-diffusion Annealing on Zn-diffused GaAs:Si, J. Appl. Phys. 74, 5493, 1993.

12. P. L. Gareso et al., Suppression of Thermal Atomic Interdiffusion in C-doped InGaAs/AlGaAs Quantum Well Laser Structures using $\mathrm{TiO}_{2}$ Dielectric Layers, J. Appl. Phys. Lett. 85, 5583, 2004.

13. I. Harrison et al., Zn Diffusion-induced Disorder in AlAs/GaAs Superlattices Semicond. Sci. Technol. 4, 841, 1989.

14. R. L. Longini, Rapid Zinc Diffusion in Gallium Arsenide, Solid-State Electron. 5, 127, 1962.

15. U. Gosele and F. Morehead, Diffusion of Zinc in Gallium Arsenide: A New Model, J. Appl. Phys. 52, 4617, 1981.

16. W. M. Theis et al., Direct Evidence for the Site of Substitutional Carbon Impurity in GaAs, J. Appl. Phys. Lett. 41, 70, 1982.

17. T. J. Leon et al., Lattice Contraction due to Carbon Doping of GaAs Grown by Metalorganic Molecular Beam Epitaxy, J. Appl. Phys. Lett. 56, 1040, 1980.

18. W. E. Hoke et al., Carbon Doping and Lattice Contraction of GaAs Films Grown by 
Conventional Molecular Beam Epitaxy, J. Appl. Phys. 69, 511, 1991.

19. C. Giannini et al., Heavy Carbon Doping of GaAs Grown by Solid-source Molecular-beam Epitaxy, J. Appl. Phys. Lett. 61, 183, 1992.

20. N. H. Ky et al., A Model for the Zn Diffusion in GaAs by a Photoluminescence Study, J. Appl. Phys. 69, 7585, 1991.

21. H. Birey and J. Sites, Radiative Transitions Induced in Gallium Arsenide by Modest Heat Treatment, J. Appl. Phys. 51, 619, 1980.

22. A. A. Bonapasta et al., The spectrum of energy levels of the Ga-vacancy/deuterium complexes in p-GaAs, J. Appl. Phys. 73, 3326, 1993.
23. S. Mokkapati et al., unpublished.

24. M. Suezawa et al., Excitation Spectra of 1200 and $1320 \mathrm{~nm}$ Photoluminescence Lines in Annealed Gallium Arsenide Doped with Silicon, J. Appl. Phys. 76, 1164, 1994.

25. I. Harrison et al., Annealing Effects on Si-doped GaAs Grown on High-index Planes by Molecularbeam Epitaxy, J. Appl. Phys. 75, 3151, 1994.

26. J. Liang et al., Studies on 0.96 and $0.84 \mathrm{eV}$ Photoluminescence Emissions in GaAs Epilayers Grown on Si, J. Appl. Phys. 79, 7173, 1996. 